\title{
Evaluation of Mechanical Properties and Medical Applications of Polycaprolactone Small Diameter Artificial Blood Vessels
}

\author{
Mahnaz Sadat Mirbagheri ${ }^{1,2,3}$, Davod Mohebbi-Kalhori ${ }^{1,2,4,5^{*}}$, Nafiseh Jirofti ${ }^{1,2,6^{*}}$ \\ ${ }^{1}$ Engineering Department, Faculty of Engineering, University of Sistan and Baluchestan, Zahedan, Iran \\ ${ }^{2}$ Biomedical Engineering Laboratory (Central Lab), University of Sistan and Baluchestan, Zahedan, Iran \\ ${ }^{3}$ Graduate Student, University of Sistan and Baluchestan, Zahedan, Iran \\ ${ }^{4}$ Nanotechnology Research Institute, University of Sistan and Baluchestan, Zahedan, Iran \\ ${ }^{5}$ Faculty of Chemical Engineering, University of Sistan and Baluchestan, Zahedan, Iran \\ ${ }^{6}$ Chemical engineering PhD Student, University of Sistan and Baluchestan, Zahedan, Iran
}

\section{*Correspondence to Davod Mohebbi-Kalhori, Chemistry Department, Faculty of Nikbakht Engineering, Sistan and Baluchestan University, Daneshgah Boulevard, Zahedan, Iran, Box: 98155987 \\ Tel: 05431136459 \\ Email: davoodmk@eng.usb.ac.ir; \\ Nafiseh Jirofti, \\ Email: nafisejirofti@pgs.usb.ac.ir}

Received July 5, 2016 Accepted March 11, 2017 Published online March 18, 2017

Please cite this article as follows: Mirbagheri MS, Mohebbi-Kalhori D, Jirofti N. Evaluation of mechanical properties and medical applications of polycaprolactone small diameter artificial blood vessels. Int J Basic Sci Med. 2017;2(1):5870. doi:10.15171/ ijbms.2017.12.

\begin{abstract}
Increasing the cardiovascular diseases and decreasing the possibility of autograft surgery are important factors that cause the choice of artificial vascular graft as an alternative treatment method. In this regard, producing artificial grafts similar to natural vessels is an important purpose that has long been followed as a gold standard by many researchers worldwide. In addition, mechanical properties including strength, long patency, bio-compatibility and hydrophobicity are necessary properties to achieve ideal vascular grafts. Hence there are various factors such as polymer type and preparation methods, which contribute to suitable mechanical properties. The electrospinning as an optimized method on one side and biocompatible, degradable and semicrystalline polycaprolactone (PCL) on the other side are used for their acceptable mechanical properties to manufacture synthetic vessels. In this study, PCL vascular grafts have been reviewed and a wide range of parameters affecting the improvement of mechanical properties and their performance have been described along with clinical applications. Therefore, by investigating and comparing single and composite PCL vascular grafts, we achieved acceptable results in the field of cell growth and adhesion as well as implanting grafts in animals such as rat and rabbit. By reviewing other studies, it was revealed that synthetic composite vessels made of PCL and natural polymers such as collagen and chitosan and synthetic polymers such as polyurethane (PU) for long patency and acceptable cell adhesion have shown good clinical results. Keywords: Vascular grafts (synthetic blood vessel), Tissue engineering, Clinical applications
\end{abstract}

\section{Introduction}

Considering the increasing rate of cardiovascular diseases worldwide, there have been many clinical demands for synthetic vascular grafts. Most of diseases that require vessels' bypass are related to atherosclerosis that leads to luminal narrowing. ${ }^{1}$ Conventional strategies in the treatment of cardiovascular diseases include angioplasty, bypass graft, and auto-graft. ${ }^{2} \mathrm{Au}-$ tologous vessels and vascular grafts, to be selected with a small diameter in bypass surgery, are proposed as golden option. But in most cases, patients cannot use this option because of various reasons, including thrombosis, spasms, limited length, poor quality and age. ${ }^{3}$ Thus, according to these conditions and large number of patients who need transplants, there are many demands for alternatives with small-diameter vascular grafts. In accordance with the treatment of these diseases, one of the treatment methods is using synthetic vascular implants. Vascular grafts ideal for clinical applications cover the following properties: desirable mechanical strength, desirable compliance, biocompatibility, non-toxicity, availability, and easy sterilization. ${ }^{4}$ Therefore, an appropriate and functional alternative small-diameter vascular graft related to auto-graft can replace inefficient available synthetic scaffolds.

Cardiovascular tissue engineering has become a promising approach in small

Copyright $($ C) 2017 The Author(s); Published by Zabol University of Medical Sciences. This is an open-access article distributed under the terms of the Creative Commons Attribution License (http://creativecommons.org/licenses/by/4.0), which permits unrestricted use, distribution, and reproduction in any medium, provided the original work is properly cited. 
diameter vessels. Synthetic polymers including polyethylene terephthalate (PET) and expanded polytetrafluoroethylene (ePTFE) have been successfully used to replace vessels with a large diameter (ID $\geq 6 \mathrm{~mm}$ ) under conditions such as low resistance and high blood flow. ${ }^{5}$ However, synthetic grafts as small diameter transplants have not provided satisfactory clinical results due to early thrombosis and occlusion. In order to address the mentioned problems in producing vascular grafts, synthetic and natural polymer materials have been widely used that provide different results regarding the mechanical properties of used polymer. There are several review articles with different viewpoints about the artificial vascular grafts. The focus of this review was not exclusively the manufacture or clinical applications separately. It investigated manufacture and clinical applications simultaneous with in vivo and in vitro tests. This paper also exhibited some offers to resolve or reduce current vascular grafts' problems. In order to evaluate mechanical and clinical performance of synthetic vascular grafts, wide range of researches were reviewed.

\section{History of Tissue Engineering}

Tissue engineering is an interdisciplinary science that uses various sciences such as engineering, biology, biomaterials, bioengineering, engineering in medicine and medicine for rehabilitation, reconstruction and replacement of damaged tissues in the body. Tissue engineering phrase was invented for the first time in 1987 by Fong, advancing the science of biomechanics and bioengineering, and then introduced in 1987 by the National Science Foundation (NSF). ${ }^{6}$ Afterwards, it has been upgraded with significant growth in various fields such as skin, bone, nerves, cartilage, heart, and blood vessels. ${ }^{7}$ The main aim of tissue engineering is to produce porous scaffolds to form natural tissues similar to the body tissues. Hence, in order to achieve the aforementioned scaffolds, many researchers have tried and achieved desirable results in the field of growth and development of tissue engineering. Regarding increased cardiovascular diseases and failure of existing treatment methods, tissue engineering has been perceived by many scientists and thus a new orientation has been made towards producing vascular grafts; thereby, calling this study as a vascular tissue engineering study. This branch of tissue engineering can analyze and propose an approach to replace the cardiovascular vessels with synthetic blood vessels and improve graft blood vessel function.

\section{A Review of Electrospinning}

By reducing polymer fiber's diameter from micron to nanometer, these kinds of fibers alert significant properties such as very high surface to volume ratio, flexibility and desirable mechanical properties compared to conventional fibers. The properties cause polymer nanofibers to be an appropriate option for many applications such as tissue engineering, drug delivery and so on (Figure 1). ${ }^{8}$ Fiber scaffold has been used in micro and nano size with

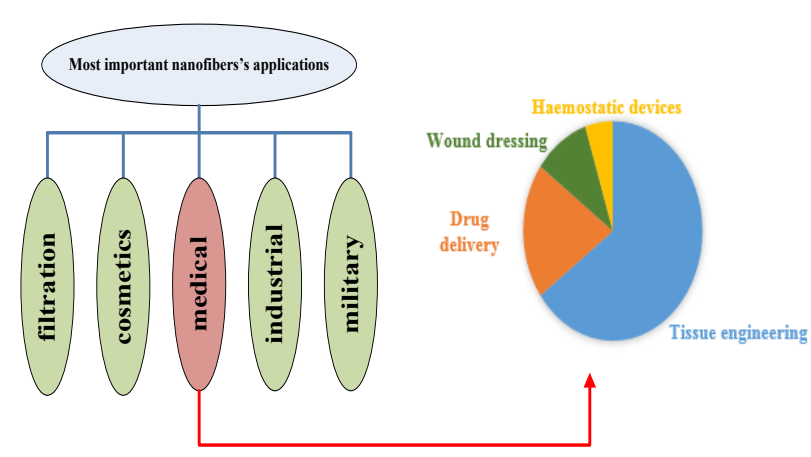

Figure 1. Different Applications of Nanofibers.

a different structure and morphology to provide an appropriate place for the growth, adhesion, and migration of cell. To consider the importance of structure and morphology to make polymer nanofibers, there are several methods including: electrospinning, phase separation, extraction, templating and so forth. It is recognized that electrospinning is the best choice based on comparison.

According to Table 1, electrospinning as a comprehensive and flexible method is able to use a wide range of polymer materials. ${ }^{9}$ The mentioned process as a statics-based method was observed for the first time in 1897 by Rayleigh and then the details were studied by Zeleny. Finally electrospinning was registered in 1934 by Formhals. ${ }^{10}$

In the process of electrospinning, after dominance of the electric field (electrostatic forces) on the surface tension of loaded solution, a continuous jet of polymer solution is formed after evaporation of the solvent absorbed in the form of continuous fibers to the collector (electrode) (Figure 2). In this process, several parameters affect the structure and morphology of polymer fibers that are classified into environmental parameters (temperature, pressure, moisture etc.), the device (voltage, gap needle to collector, flow etc.) and polymer solution (solution concentration, solvent type, dielectric constant etc.). ${ }^{11}$

\section{Polycaprolactone Vascular Scaffolds}

The necessity of using polymer materials to make a vas-

Table 1. Nanofibers' Production Methods

\begin{tabular}{|c|c|c|}
\hline Method & Advantages & Disadvantages \\
\hline Electrospinning & $\begin{array}{l}\text { 1. Cost effective } \\
\text { 2. Control over fiber } \\
\text { diameter } \\
\text { 3. Vast material selection }\end{array}$ & $\begin{array}{l}\text { 1. Toxic solvents often } \\
\text { use } \\
\text { 2. Poor cell infiltration } \\
\text { into the core of the } \\
\text { scaffold }\end{array}$ \\
\hline $\begin{array}{l}\text { Phase } \\
\text { separation }\end{array}$ & $\begin{array}{l}\text { 1. 3-Dimentional pore } \\
\text { arrangement }\end{array}$ & $\begin{array}{l}\text { 1. Lack of control of } \\
\text { fiber arrangement } \\
\text { 2. Complex procedure }\end{array}$ \\
\hline Extraction & 1. Natural materials & $\begin{array}{l}\text { 1. Limited material } \\
\text { selection } \\
\text { 2. Limited control of } \\
\text { fiber diameter and } \\
\text { length }\end{array}$ \\
\hline Templating & $\begin{array}{l}\text { 1. Vast material selection } \\
\text { 2. Control over fiber } \\
\text { diameter and length }\end{array}$ & $\begin{array}{l}\text { Limitation on fiber } \\
\text { dimensions and } \\
\text { arrangement }\end{array}$ \\
\hline
\end{tabular}




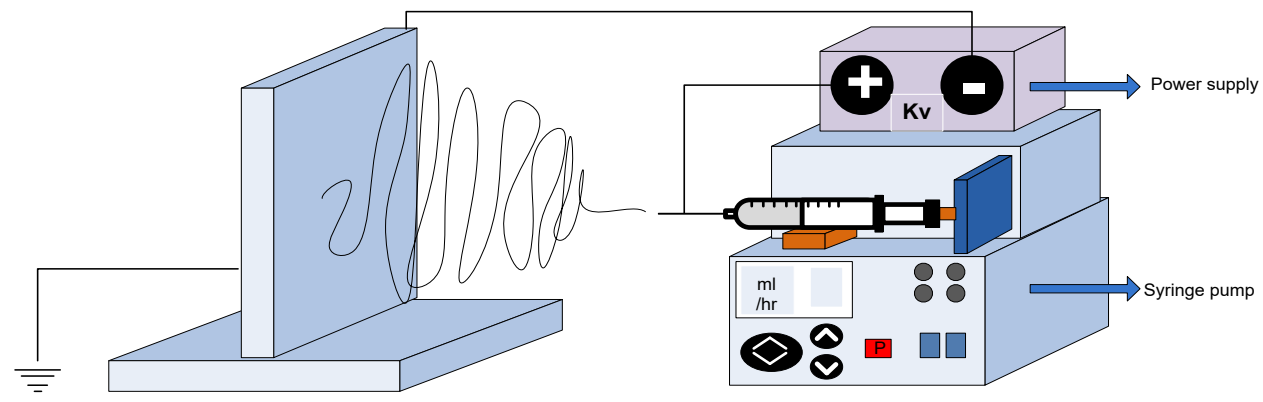

Figure 2. Schematic Representation of Electrospinning.

cular scaffold in tissue engineering is inevitable. The selected appropriate polymer should reflect all desired properties such as elastic properties, cell adhesion, and bio-mechanical properties. Thus, selecting an appropriate polymer is one of the most essential parameters of vascular graft tissue engineering. ${ }^{12,13}$

Common appropriate polymers for vascular grafts are divided into 2 natural and synthetic categories. Natural polymers usually are biocompatible, cheap and available, and in comparison with synthetic polymers have a structure that is appropriate for growth and cell adhesion and thus creating tissue. ${ }^{14}$ The most important natural polymers are collagen, gelatin, chitosan, fibrin, and elastin. In contrast, there are synthetic polymers that are produced by different techniques and classified into 2 biodegradable and non-biodegradable groups..$^{15}$ In terms of undesirable mechanical properties, lack of flexibility of synthetic polymers, and besides, unavailability of natural polymers, are the main causes of attention to synthetic polymers in manufacturing vascular grafts. However, it should be noted that controlling molecular weight in synthetic polymers due to their chemical synthesis is easy and it can affect the physical properties including degradability. ${ }^{14,16}$ Although in the field of producing vascular scaffolds with a large diameter and low resistance, the use of non-degradable polymers like ePTFE and PET led to satisfying results but due to lack of proper dilation and short term durability in the body, the vascular scaffolds failed in the case of small-diameter vessels., ${ }^{5,17-19}$ In this regard, achieving a polymer that can lead to the manufacture of a small diameter vascular scaffold with biomechanical properties similar to normal vessels is a goal that a large number of researchers attempt to achieve.

Many synthetic polymers in the area of production of vascular scaffolds have been studied and analyzed that are used individually or as a composite. Polyurethane (PU), polycaprolactone (PCL), PET, polyvinyl acetate (PVA), polyethylene oxide (PEO) etc, are the commonest polymers, among them PU, PCL, and PET have attained more successful and satisfying results in this field. PU as an elastic and biodegradable polymer can be successfully used in the realm of small-diameter scaffolds. ${ }^{19,20}$ PET also due to its good tensile strength is widely used to make synthetic scaffolds..$^{21,22}$ PCL as a biodegradable and hydrophobic polymer with desirable physical and mechanical properties and high flexibility has also obtained a special position in tissue engineering applications (Table 2). This semi crystalline polymer is taken into consideration due to its high solubility as well as combination with other polymers. $^{23,24}$ Hence, according to the mentioned specifications as well as low speed of degradation and superior rheological properties of PCL compared to its counterparts, it is used as a suitable option for a wide range of mentioned applications and implants. ${ }^{25}$

Among the applications of tissue engineering, vascular grafts are especially important. Synthetic vessels are tubes with different diameters which replace a part of natural vessels that are not able to perform well due to the diseases. Therefore, achieving a suitable technology to access synthetic vessels with beneficial mechanical properties and maximum compliance is one of the requirements of tissue engineering. To this end, researchers around the world are trying to achieve ways and materials based on nanotechnology and tissue engineering techniques to solve existing synthetic vessels' problems especially in the field of vessels with a small diameter and produce a scaffold with the most similarity to natural blood vessels. In this field, PCL polymer has been regarded for desirable mechanical properties and optimized biocompatibility that can easily convert to micro and nanofibers by electrospinning and form scaffold with approved shape..$^{27}$

Since tissue engineering suggests a unique method to overcome medical problems such as replacing damaged organ or tissue, compatibility of grafted vessels in the human and/ or animal body is the main goal in accomplished studies. Therefore, to achieve the mentioned goal, many studies have been conducted in different branches and cases such as mechanical and biological properties of

Table 2. Properties of Polycaprolactone ${ }^{26}$

\begin{tabular}{ll}
\hline Properties & Range \\
\hline Average molecular weight $(\mathrm{g} / \mathrm{mol})$ & $530-630000$ \\
Density $\left(\mathrm{g} / \mathrm{cm}^{3}\right)$ & $1.071-1.2$ \\
Glass transition temperature $\left({ }^{\circ} \mathrm{C}\right)$ & $(-65)-(-60)$ \\
Melting temperature $\left({ }^{\circ} \mathrm{C}\right)$ & $56-65$ \\
Decomposition temperature $\left({ }^{\circ} \mathrm{C}\right)$ & 350 \\
Inherent viscosity $\left(\mathrm{cm}^{3} / \mathrm{g}\right)$ & $100-130$ \\
Tensile strength $(\mathrm{MPa})$ & $4-785$ \\
Young modulus $(\mathrm{GPa})$ & $0.21-0.44$ \\
\hline
\end{tabular}


polymeric scaffolds.

\section{Morphology, Mechanical and Biological Properties of PCL Scaffold}

As previously mentioned, every polymer that is used to replace and repair tissue needs to have mechanical and biological properties similar to natural vessels. These requirements in the production of synthetic blood vessels are considered as follows: Biocompatible, non-stimulator of the immune system, non-toxic, compliant in the range of natural blood vessels and strong to stand suture.

Generally, in order to achieve synthetic blood vessels that could be considered as a desirable clinical product for tissue engineering, we should assess mechanical and biological properties, structure and morphology of scaffolds, and analyze the effect of various parameters on their reaction. PCL is a biocompatible polymer with long degeneration period that is one of the reasons of its selection to make different prostheses in tissue engineering. Many studies have been conducted in the field of single, composite, and even copolymer PCL scaffolds which indicate high potential of this polymer in the development of tissue engineering. In order to make PCL prostheses, many parameters such as mechanical properties, fiber morphology, cell adhesion, tissue regeneration and its compatibility with the body have been perceived.

The Structure and Morphology

The first step to verify the efficiency of scaffolds is to examine the structure and morphology. The most important structural properties of vascular scaffolds affecting tissue repair and cell infiltration are porosity, pore size as well as fiber diameter. The mentioned factors can bring about changing properties of synthetic blood vessels influenced by a wide range of operating parameters. One of the factors that can affect the mentioned properties is electrospinning conditions. Voltage, solution concentration, solvent type, collector to needle distance and solution flow rate can have a great effect on fiber's properties. One of the key features which influences the structure and then electrospinning scaffold properties is the average fiber diameter. Type of solvent as well as solution concentration heavily affect fiber diameter and thickness. For this reason, some scholars use different solvents for PCL to achieve fibers with diameters of nano and a unique structure. In this regard, Kanani and Bahrami ${ }^{28}$ could examine the effect of solvent type as well as simultaneous effect of solvent, concentration, and voltage on fiber morphology using glacial acetic acid, acetic acid 90\%, mixture of methylene chloride and dimethyl, formic acid as well as mixture of formic acid and acetone in different concentrations of $5 \%, 10 \%, 15 \%$, and $20 \%$. It was disclosed that in the concentration of $5 \%$, solutions made of formic acid as well as mixture of formic acid and acetone, due to low viscosity after exiting the syringe and being placed in an electric field, not only produced no fiber but also remained in the form of droplets on the collector. However, using other solutions in this concentration resulted in beaded fiber production (Figure 3). Another important factor evaluated in this study was a change in the fiber diameter due to the increased applied voltage. For this purpose, by applying the voltages of 10,15 and $20 \mathrm{kV}$, they
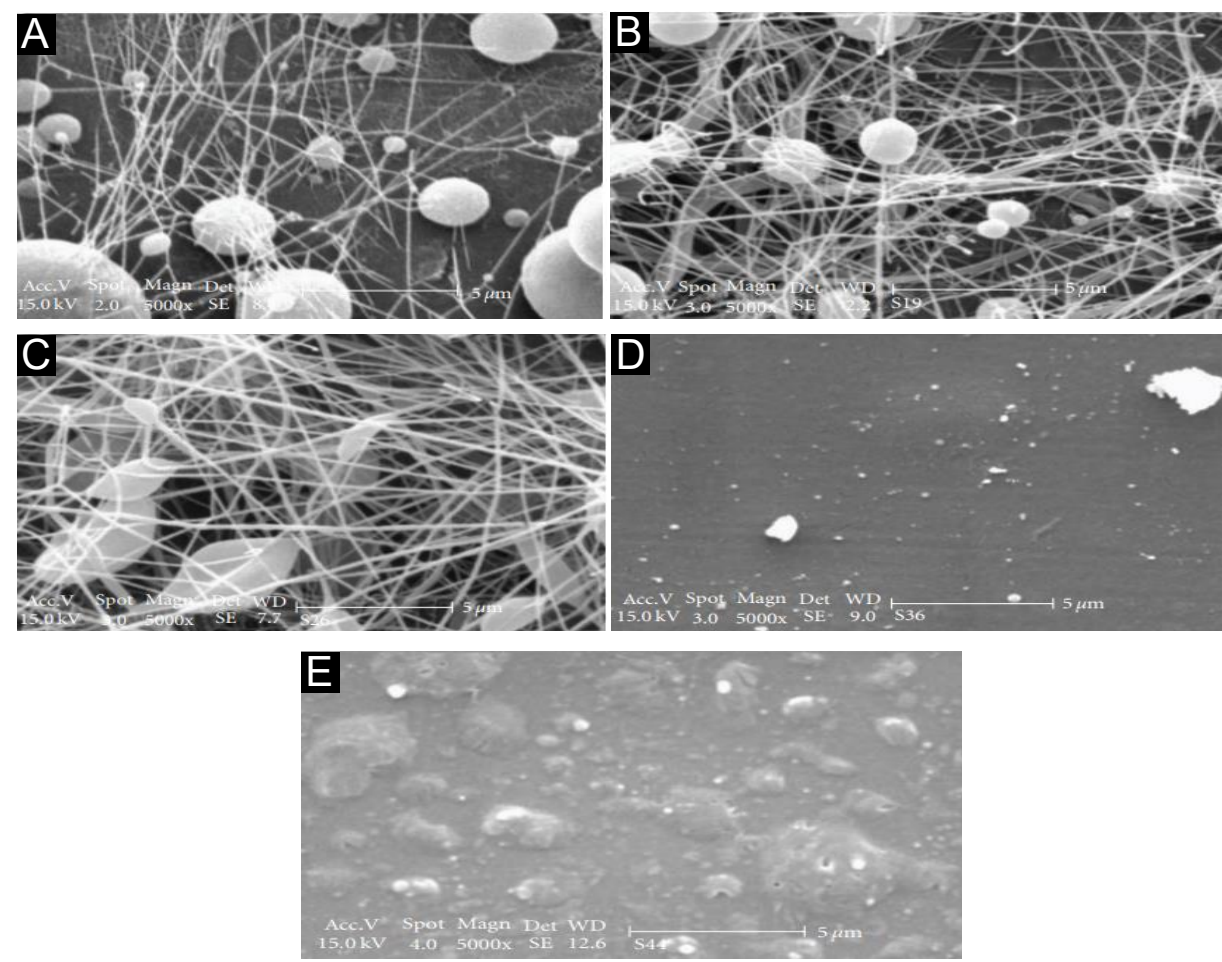

Figure 3. Effect of Solvent Type on PCL Fiber Morphology (Concentration = 5\%). (A) Glacial Acetic Acid, (B) 90\% Acetic Acid, (C) Methylen Ghloride/DMF = 4/1, (D) Glacial Formic Acid, (E) Formic Acid/Acetone = 4/1. 
observed increased fiber diameter (Figure 4). In addition, it was observed that increasing the solution concentration caused increased fiber diameter and also reduced number of beads after deformation from spherical to fusiform (Figure 5).

In this regard, other studies have been conducted on the solvents of acetone and mixture of acetic acid and triethylamine to make synthetic PCL in different concentrations, and check its effect on the morphology and structure of nanofibers. After reviewing the results, it was found that optimized concentrations to make uniform fibers for acetone and mixture of acetic acid and triethylamine, were $17 \%$ and $11 \%$ of the weight, respectively. ${ }^{29}$ Another common solvent for PCL is chloroform. Van der Schueren et al used chloroform and mixture of acetic acid and formic acid as solvent and after comparing the results, they observed that the fibers' diameter for the mixture solvent system was ten times smaller than the case in which the chloroform was used. ${ }^{30}$

The main reason of changed fiber average diameter can be attributed to the difference in solvent dielectric constant (Table 3), as the solvent properties strongly affect the morphology of the fibers. In this regard, Lee et al examined the effects of solvents of methylene chloride, a mixture of methylene chloride and dimethylformamide as well as a mixture of methylene chloride and toluene, and

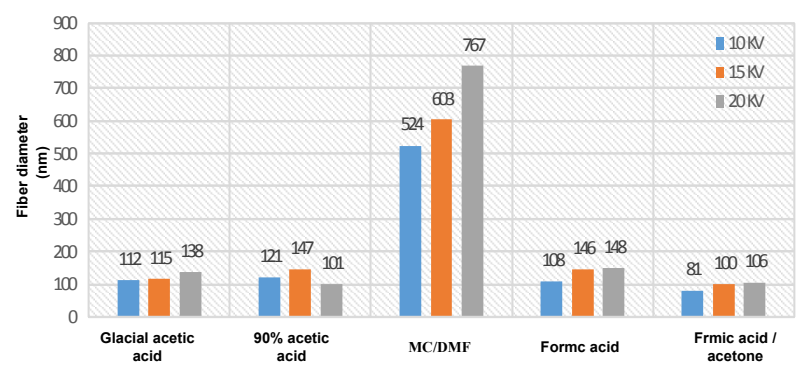

Figure 4. Effect of Voltage Increase on Fiber Diameter.

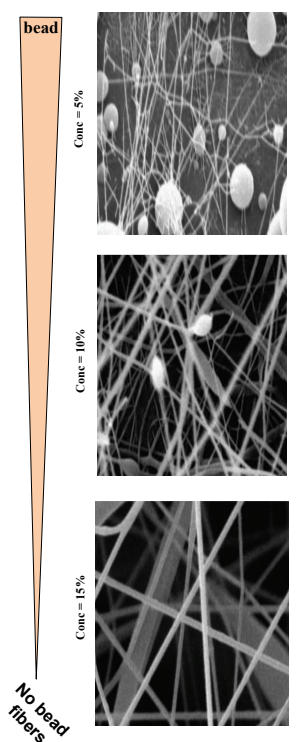

Figure 5. Effect of Concentration Increase on Bead Number and Fiber Diameter. found that the fiber average diameter of methylene chloride was about $5500 \mathrm{~nm}$, and for a mixture of methylene chloride and dimethylformamide was equal to $200 \mathrm{~nm}$. However, according to high viscosity and low conductivity coefficient in a mixture of methylene chloride and toluene, the formation of fibers by electrospinning was problematic. In addition to these results, it was reported that using DMF solvent was successful due to its high dielectric constant. ${ }^{31}$ With a plurality of investigations done by researchers about solvent types in PCL electrospinning, it was announced that fiber diameter was strongly dependent on the solution concentration or amount of PCL (Figure 6 and Table 4). ${ }^{28,30,32}$

By changing the fiber's diameter, porosity and pore size were also changed. Scaffolds with larger diameter has higher porosity and larger pore size. ${ }^{34}$ Wang et al following a study on thicker fibers with high porosity of PCL concluded that by increasing the fiber diameter, pore size would also increase and cells can easily infiltrate into the scaffold. This is opposite the fact that in the thin fibers only surface cell growth was observed..$^{35}$

Table 5 summarizes the PCL electrospun fiber morphology as well as relation among the type of solvent, concentration, and the average fiber diameter. According to this table, using a blend of formic acid and acetone in the concentration $10 \%$ leads to the production of very thin fiber with some beads.

\section{Mechanical Properties}

PCL scaffolds have acceptable mechanical properties in the range of natural vessels. The most important properties are tensile stress, tensile strain, compliance, burst pressure, strength and suture retention. One of the most

Table 3. Dielectric Constant of Polycaprolactone Solvents ${ }^{33}$

\begin{tabular}{lc}
\hline Solvent & Dielectric Constant at $\mathbf{2 0}^{\circ} \mathbf{C}$ \\
\hline Acetic acid & 6.2 \\
Formic acid & 58 \\
Methanol & 32.6 \\
Ethanol & 22.4 \\
Methylene chloride & 9.1 \\
Toluene & 2.4 \\
Chloroform & 4.8 \\
Acetone & 20.6 \\
Water & 79.7 \\
Dimethylformamide & 36.7 \\
\hline
\end{tabular}

Table 4. Effect of Concentration and Humidity on Average Diameter

\begin{tabular}{|c|c|c|}
\hline \multirow{2}{*}{$\begin{array}{l}\text { Concentration } \\
(\%)\end{array}$} & \multicolumn{2}{|c|}{ Average Fiber Diameter (nm) } \\
\hline & Relative Humidity $10 \%$ & Relative Humidity $\mathbf{5 0} \%$ \\
\hline 12 & $297 \pm 49$ & $271 \pm 78$ \\
\hline 13 & $410 \pm 64$ & $355 \pm 126$ \\
\hline 14 & $445 \pm 79$ & $364 \pm 83$ \\
\hline 15 & $610 \pm 139$ & $392 \pm 106$ \\
\hline 16 & $798 \pm 188$ & $418 \pm 86$ \\
\hline 17 & $966 \pm 198$ & $463 \pm 108$ \\
\hline
\end{tabular}




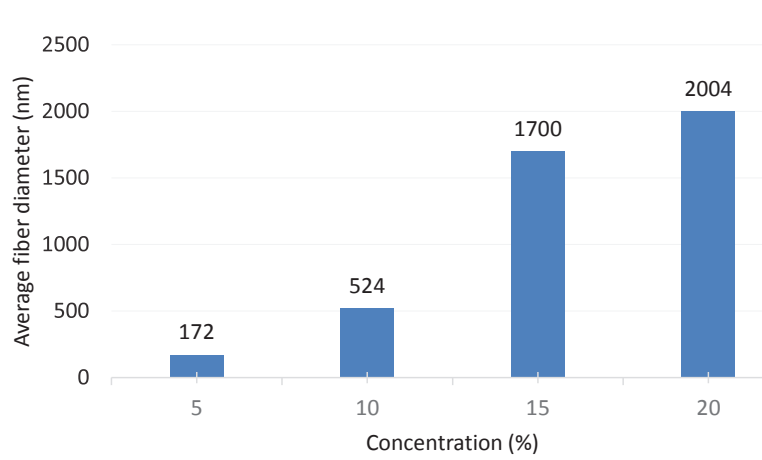

Figure 6. Effect of Concentration Increase on Average Fiber Diameter.

important mechanical properties to appraise the resistance of vascular grafts against the fluctuations in blood pressure is burst pressure. In a study done by Drilling et al in 2007, important mechanical properties such as burst pressure, suture retention strength, and tensile strength of electrospinning scaffolds of PCL were examined and compared with proportional values in the natural vessels. In this study, the researchers showed that the amount of pressure significantly depended on the concentration of the solution. Therefore, they reported a moderate amount for this parameter equal to $4000 \mathrm{~mm} \mathrm{Hg}$, and by comparing the value of the parameter in natural vessels $(2000 \mathrm{~mm}$
$\mathrm{Hg}$ ) showed that the mechanical properties of PCL fibers were compatible with those of natural vessels. ${ }^{36}$ According to the presented results, it can be concluded that by increasing the concentration, desirable mechanical properties such as tensile and stress can be achieved. However, in order to improve and modify PCL biomechanical properties, another group of researchers used thermal treatment method and did thermal operations at temperatures of 54 to $55^{\circ} \mathrm{C}$, and observed that tensile, burst pressure, and suture retention significantly increased..$^{37}$

\section{Biological Properties and Clinical Applications}

Although the mechanical properties of the artificial blood vessels and their similarity to natural vessels is a major step, the effect of biological conditions on the vessel cannot be overlooked. The final goal of producing vascular grafts is to measure the adhesion and infiltration of cells to form a new tissue. Thus vascular grafts should become a natural tissue after being replaced in the body and have a performance similar to natural vessels. One of the factors in this context is to examine the adhesion, infiltration, and diffusion of cells on the scaffold for the formation of new tissue.

Adhesion and Spreading of Cells

Fiber's hydrophilic property plays a crucial role in the

Table 5. Concentration and Solvent Effect on Polycaprolactone Fibers' Morphology

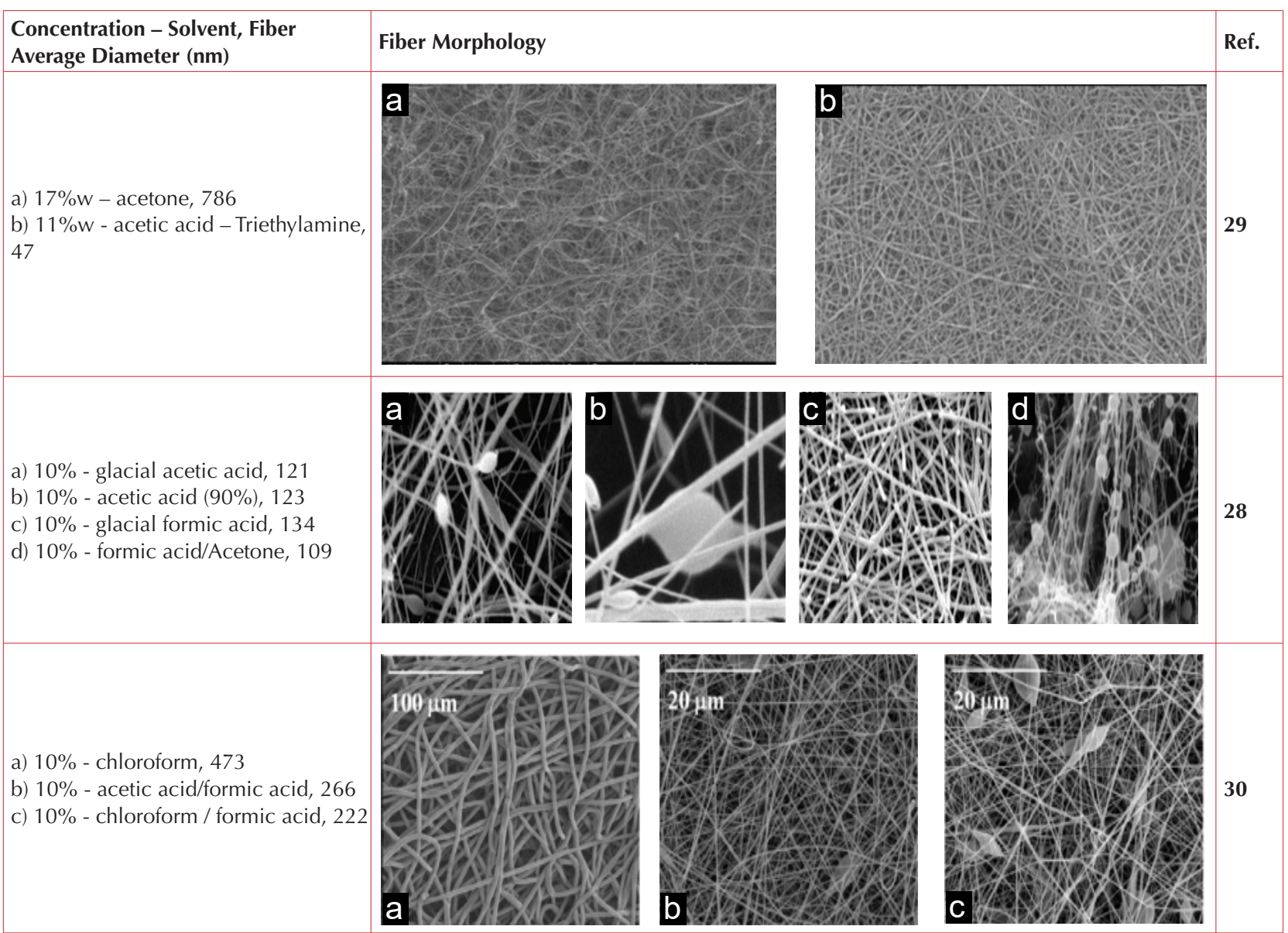


growth, proliferation, and infiltration of cells. Then the formation of new tissue should be considered. This property is obtained by measuring the ratio of contact angle of water droplets to scaffold surface (Figure 7). Due to the hydrophilic nature of PCL, vascular grafts made of this polymer may fail to absorb and infiltrate cells. In order to improve this undesirable property and increase its hydrophilic property and finally improve the adhesion and migration of cells on the scaffold, researchers are seeking the methods to solve the problem. The general methods used for producing scaffold can be combined with simultaneous use of hydrophilic polymers (natural/synthetic) to modulate the properties of the scaffold, cover the scaffold with other active substances and use methods of surface modification including plasma and alkaline hydrolysis (Table 6).

Alkaline hydrolysis is one of the methods in which an appropriate environment is made for the growth and proliferation of cells to modify the hydrophobic surface of PCL by placing scaffold in alkaline solution $(\mathrm{NAOH}){ }^{38}$ In a study, the adhesion effect of keratinocytes and fibroblasts on the surface of modified electrospun PCL with alkaline hydrolysis was studied and compared with PU scaffold and different natural polymers. According to the results of this study, in addition to the great effect of cells' adhesion and influence of the modified scaffold in comparison with unmodified samples, small changes were observed in the cell adhesion to other polymer scaffolds. ${ }^{39}$ As previ-

Table 6. Effect of Different Surface Treatment Methods on Cell Attachment

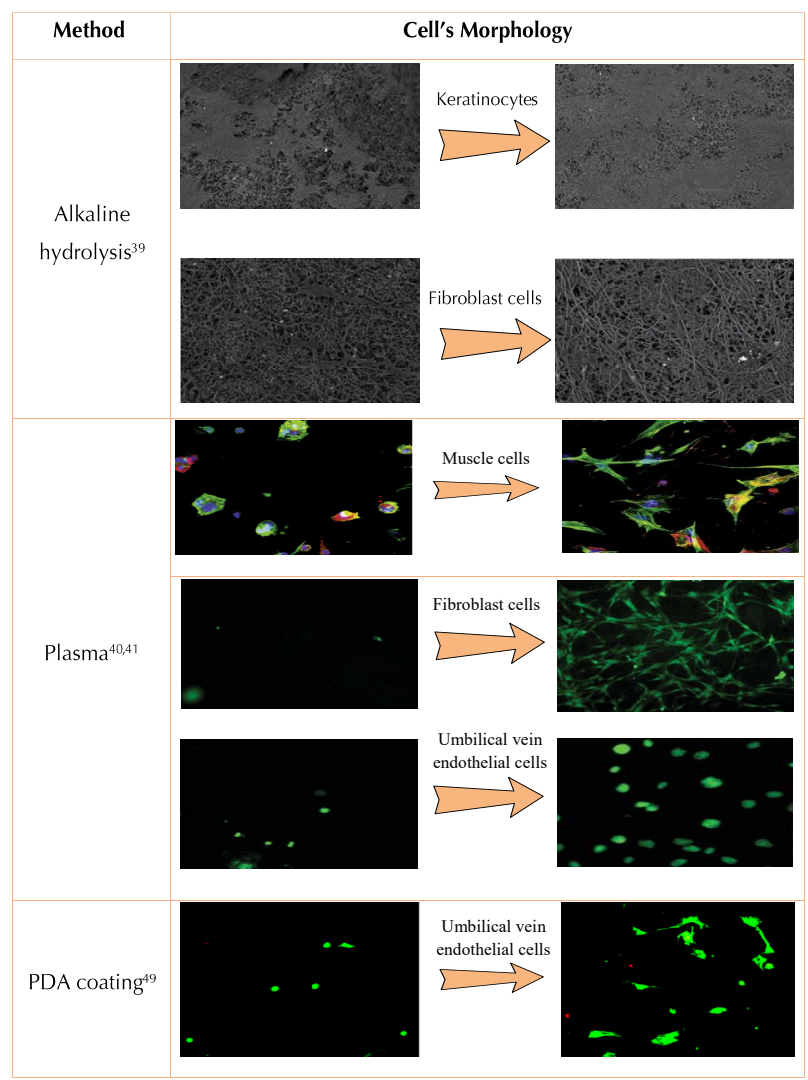

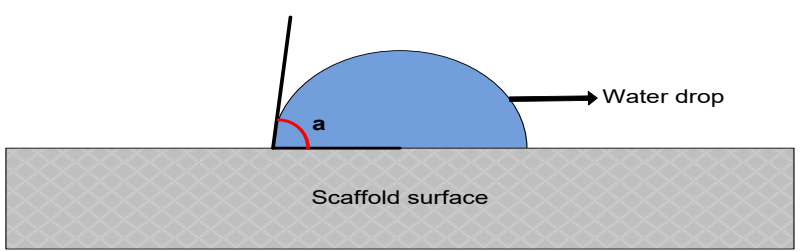

Figure 7. Water Contact Angle.

ously mentioned, plasma surface modification method is a functional method to increase the hydrophilic property of PCL. To improve their previous studies in the field of vascular scaffolds of PCL, ${ }^{27,34}$ de Valence et al used plasma method to modify the surface of scaffold and implanted the scaffolds with the length of $1 \mathrm{~cm}$ and a diameter of $2 \mathrm{~mm}$ in a mice body for 3 weeks. However, the results showed fixed diameter after 3 weeks, and mechanical properties of fibers after applying plasma method, the scaffold hydrophilic property, and muscle cells absorption were increased acceptably. While, signs of obstruction were seen on modified scaffold after the given period. But unmodified scaffold had acceptable patency. ${ }^{40}$ In this regard, after producing PCL porous hollow membrane, in order to provide an appropriate substrate to increase cells' growth and form new tissue, Hadjizadeh and Mohebbi-Kalhori also used plasma to modify the surface and human umbilical endothelial cells and fibroblast cells to evaluate the adhesion of the above cells. By observing an increase in this amount after plasma, they found that using this type of scaffold can be effective on improving the tissue engineering. ${ }^{41}$

Fibrin as a natural polymer has further helped in improving the PCL scaffold. To achieve arranged PCL fibers, Zhou et al began the electrospinning of different concentrations of the polymer solution. In order to achieve arranged and uniform fibers, the collector with the speed of $700 \mathrm{rpm}$ was used and then electrospun fibers were covered with fibrin. After reviewing the results of the cell culture, it was found that cells were in line with arranged fibers covered with fibrin and this caused more cells' proliferation and diffusion. ${ }^{42}$

Another research was conducted in order to increase the material bulk absorption by creating surface channels on the electrospun PCL scaffold via laser. Different frequencies caused channel creation and cavities on the scaffold and thus by surface modification, hydrophilic property was somewhat increased. ${ }^{43,44}$ Another factor that affects cell infiltration is vascular scaffolds' wall thickness. For this purpose, a team of researchers after electrospinning the PCL microfibers, began spinning PCL nanofiber on previous scaffolds and by increasing the electrospinning time, found different thicknesses. According to the thickness of nanofiber layer increased over time, they found that growth and spread of cells on the surface of vascular scaffolds was increased but their infiltration was reduced. ${ }^{45}$

Endothelium is a thin layer of cells that covers the inner layer of blood vessels. The formation of this layer in blood 
vessels prevents blood from coagulation. Since one of the problems related to grafted ePTEF and PET synthetic vessels is obstruction after a short time ${ }^{46}$ many studies have been conducted to solve the problem. In this regard, Serrano et al. examined the effect of cultured muscle cells as well as endothelial cells on modified PCL films by alkaline hydrolysis and evaluated the behavior of these 2 cell types as a pilot study to develop vascular graft and found that alkaline hydrolysis increased the orientation and expansion of both cell types on the surface of the film..$^{38}$ In order to increase the formation of endothelial cells as well as to prevent hyperplasia in small-diameter vessels, controlling the patency is essential. For this purpose, studies have been carried out on the electrospinning of a mixture of PCL and CGA peptides with great tendency for the growth of endothelial cells, and the factors affecting the formation of endothelial cells were examined. The results indicated high capability of CGA to accelerate the formation of endothelial layer. ${ }^{47}$

In order to coat PCL vascular scaffolds, a group of researchers used arginine-glycine-aspartic acid (RGD) to coat the scaffold and then replaced an equal number of modified prostheses and unmodified prostheses for 2 and 4 weeks within the rabbits' carotid artery. Their results showed that in addition to an increase in the amount of endothelial cells, it was observed that all modified prostheses had patency, while 4 of 10 unmodified prostheses had thrombosis. Moreover, according to the results of scanning electron microscope (SEM) images, adhesion of a large number of platelets attracted researchers' attention. Therefore, they observed that the use of RGD as a surface coating for PCL fibers caused rapid cell growth and infiltration and hence less accumulation of blood platelets at the local level and further patency. ${ }^{48} \mathrm{Ku}$ and Park also coated $700 \mathrm{~nm}$ fibers of PCL with polydopamine (PDA) and gelatin, then used umbilical endothelial cells for cell culture test to compare water contact angle with the surface of scaffold and thus the rate of increasing the hydrophilic property of fibers. The results showed that the use of PDA had a desirable effect on PCL scaffold and improved fibers' surface in order to accept endothelial cells. ${ }^{49}$ In this regard, for endothelial cells' infiltration and increasing the compatibility, a number of researchers put modified PCL scaffold in gelatin solution for 24 hours and found the cells orientation successfully. ${ }^{50}$

Heparinized vascular graft is another method to reduce blood coagulation and fiber's morphology study. For this reason, by adding a certain amount of heparin to PCL solution and spinning this mixture, many researchers could examine fibers' morphology, surface resistance, and blood coagulation, and observe an increase in cell proliferation. They also reported a direct relation between heparin concentration and PCL fibers' diameter, because of increasing solution electrical charge due to an increase in heparin. ${ }^{51,52}$

In a comparison between PCL and ePTFE prostheses with a diameter of $2 \mathrm{~mm}$, the patency of PCL and ePTFE was $100 \%$ and $67 \%$, respectively. Moreover, the compliance of PCL prosthesis in a certain pressure was significantly more than that of ePTFE prosthesis. Hence PCL, as previously predicted, can show better capabilities in the field of small-diameter vascular grafts. ${ }^{53}$ This result was seen in the replacement and implantation of electrospun $15 \mathrm{wt} \%$ PCL as vascular prostheses. ${ }^{27}$ In another study, by changing and optimizing electrospinning conditions and polymer solution with PCL concentration of $12 \%$ in solvents' mixture of chloroform and ethanol (7:3), vascular prostheses were produced with diameters of 2 and $4 \mathrm{~mm}$ that showed acceptable patency and mechanical properties. ${ }^{32}$ To examine clinical applications of individual prostheses, de Valence et al managed the porosity and fiber diameter by changing the electrospinning conditions such as solution concentration, voltage and flow rate, in order to manufacture a vascular graft with a diameter of $2 \mathrm{~mm}$ and a porous layer in different arrangements. After testing cell's growth and infiltration on prostheses' surface, they found that a low-porous layer as a vessel external layer, due to its small pore size, had poor cell diffusion and infiltration. They also carried out several in vivo tests and observed a successful implantation with good patency, no blood leakage during the surgery, and absence of thrombosis. ${ }^{34}$ In another study conducted by the same researchers, vascular degradability in the body was investigated at short time intervals. For this purpose, a PCL scaffold with a diameter of $2 \mathrm{~mm}$ was implanted by abdominal aorta in a male mouse at intervals of $1.5,3,6,12$, and 18 months. No thrombosis, patency and limited hyperplasia were observed as results. Furthermore, they found increased cell attachment during the first 6 months, but decreased cell number during 12 and 18 months. ${ }^{27}$

Composite Scaffolds and Evaluation of Clinical Application It is obvious that a polymer material cannot independently meet all functional needs of a scaffold for an optimized application in tissue engineering. Most of synthetic and natural polymers are hydrophobic, with different properties. Since an ideal vascular graft should have properties akin to natural vessels, in order to optimize the synthetic scaffold, a combination of two or more synthetic or natural polymers can be used. One of the composite prostheses considered in recent years is natural polymer of collagen composite with synthetic polymer of PCL. The morphology of electrospun composite fibers as well as cell's infiltration on the surface were measured and evaluated in comparison to single PCL prostheses. ${ }^{54-57}$ In this regard, Tillman et al succeeded to electrospin a composite vascular graft containing PCL and collagen with a diameter of $4.75 \mathrm{~mm}$. Some important factors such as cell growth and infiltration and tolerating physiological conditions were checked by implanting the scaffold in rabbit aortic bypass. This composite scaffold in addition to good performance regarding the acceptance and growth of endothelial and muscle cells, also had a good patency. by comparing the tensile strength of scaffold with the natural vessels, they found that the tensile strength of scaffold was reduced a little after a month, though comparable to 
natural vessels. ${ }^{58}$

Regarding good effect of composites, another group of researchers in 2011 examined the effect of composite vascular scaffolds of PCL and elastin (diameter 2.8) in the rabbit's body. They cut a piece of carotid and replaced composite scaffold in the animal's body for a month. No leakage of blood during surgery, suturing as well as physical properties were observed compared to previous implantation. ${ }^{59}$

Another natural polymer that is used in combination with PCL is chitosan. In order to achieve optimum fiber structure and morphology, it has been examined in numerous studies. In this regard, Hong and Kim achieved acceptable results in biomechanical properties, by layer and simultaneous spinning of PCL and chitosan. They reported an increased ratio for Young's modulus parameters and cell proliferation ( $75 \%$ and $25 \%$, respectively) and introduced chitosan as an excellent choice for various applications in tissue engineering. ${ }^{60}$ Another composition is a combination of 2 synthetic polymers of PCL and PU. In a study which was conducted based on a sample of this compound, PCL fibers were prepared by wet spinning method and then PU fibers were produced as a layer through electrospinning to examine cell infiltration and endothelial layer formation. After cell culture experiment and reviewing the results, adhesion and rapid formation of endothelial layer were observed. ${ }^{61}$ Therefore, the use of elastic PU polymer can also be useful for improving PCL properties. Based on this result, by electrospinning of a combination of 2 polymers of PU and PCL for making vascular scaffolds and measuring mechanical and hydrophilic properties, Nguyen et al reported acceptable results. They also used cultured fibroblast cells and endothelial cells of bovine pulmonary artery on the surface of the composite vascular graft and observed that use of this type of scaffold would increase the proliferation of cells. ${ }^{62}$ Studies on some other polymeric compositions have investigated the effect of polymers on the PCL. In an experiment conducted on 3-layer scaffold, researchers used different combinations of 3 polymers of PCL, elastin, and collagen and made a 3-layer scaffold with a diameter of $2 \mathrm{~mm}$, similar to the body's natural vessels, and tested its similarity to natural vessels. To this end, for each of the three layers, different percentages of the mentioned polymer were used. The amount of stress and compliance were measured and reported in the range of natural vessels. ${ }^{63}$ Composite scaffold morphology and implanted grafts are presented in Tables 7 and 8, respectively.

\section{Conclusion}

Regarding acceptable biomechanical properties of PCL in comparison to other synthetic polymers, and great records on various applications of tissue engineering as well as the necessity and importance of using vascular scaffolds, the synthetic blood vessels and their influencing factors have been studied to improve biomechanical properties and clinical performance. By reviewing the research conducted in the area of clinical applications of PCL synthetic vessels and comparing them, important parameters such as electrospinning conditions, specifications of polymer solution (concentration, solvent type, solvent ratio, etc.), and surface modification techniques have been declared and their effect on the structure and morphology of the fibers as well as development and infiltration of cells and thus new tissue formation were compared. The results can be briefly described as follows:

- In order to optimize mechanical and biological properties of vascular scaffolds, we can either change the parameters of electrospinning, the solution conditions, or both. By comparing the effects deduced from changes in the mentioned parameters, it is understood that changing the solution concentration as well as the type of solvent is more important than changing the electrospinning conditions. Because it further affects the morphology and structure of the PCL fibers.

- To access uniform and bead free fibers, high concentrations of this polymer could be used in the solution.

- In comparison of the solvents, it was found that chloroform, acetic acid, methylene chloride, and acetone are efficient solvents for PCL, and solvents such as DMF, ethanol, methanol, and water are used to increase the conductivity and dielectric coefficient of the solution and reduce the volatility of other solvents. The SEM images as results also indicate larger fiber diameter using chloroform as a solvent.

- Using a combination of PCL polymers and other polymers (natural or synthetic) to manufacture a composite scaffold, we may achieve further improved and modified desirable mechanical and physical

Table 7. The Morphology of Composite Scaffolds

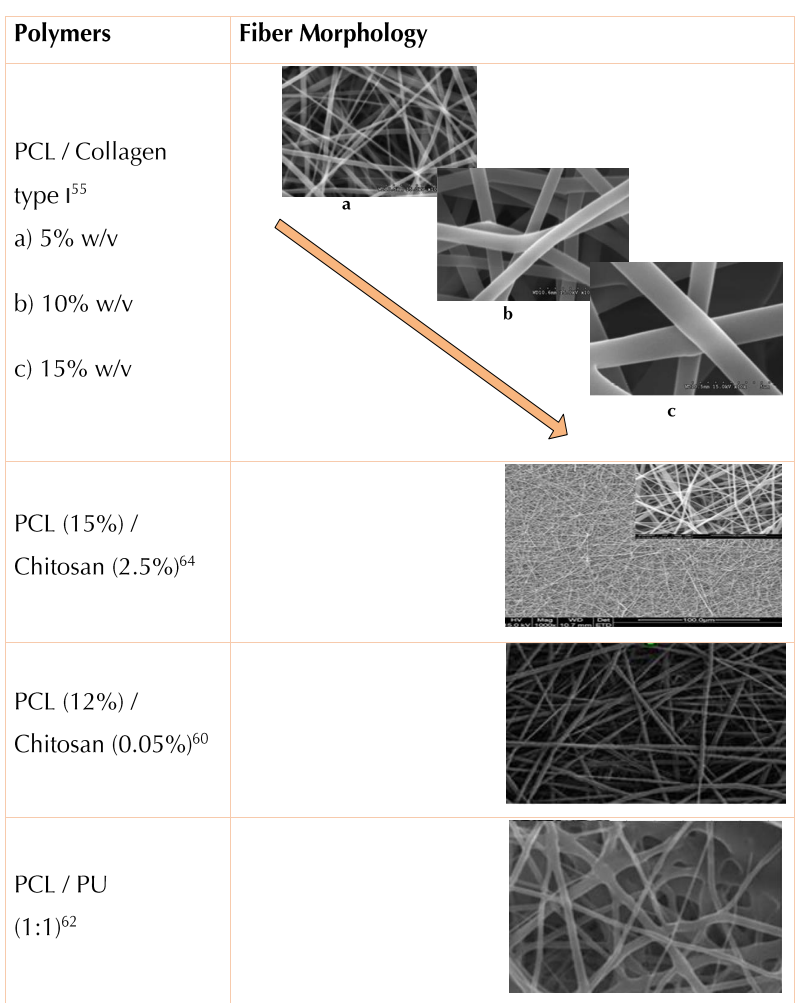


Table 8. Some Implanted Scaffolds

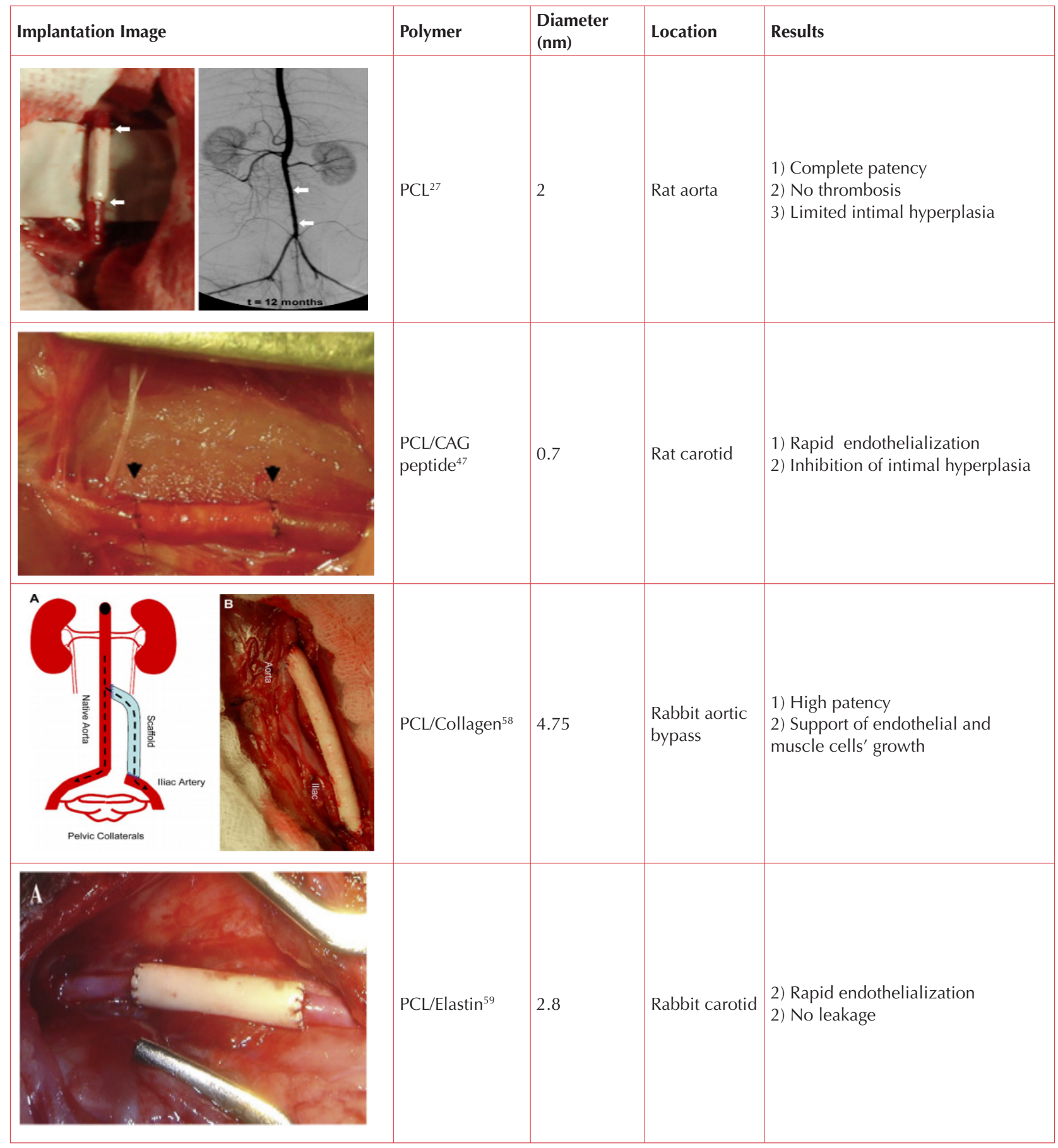

properties. Natural polymers of collagen and chitosan as well as PU synthetic polymer are the ones that have provided good results in improving PCL scaffold.

- $\quad$ For increasing PCL hydrophilic property and thus further cell adhesion on its surface, methods such as alkaline hydrolysis, plasma, scaffold coating with activated substances such as PDA and/or created scratches on the scaffolds by laser could be employed.

- By adding heparin to the PCL solution and/or using vascular scaffolds immersed in a solution of heparin, biological properties of single and composite PCL scaffolds can be improved in the body and disorders such as thrombosis, aneurysm and intimal hyperplasia can be reduced.

- Based on implanted PCL grafts (single and composite), some results like no blood leakage during the surgery, good patency, endothelial layer formation and no thrombosis were observed by researchers.

In conclusion, considering the above results, it can be stated that PCL is a widely used polymer that can satisfy many requirements in tissue engineering including vascular scaffolds. Using the results of studies carried out in this field as well as considering some of the desirable 
and undesirable properties of the polymer and increased scaffold durability time in the body, we can take effective steps on improving their clinical applications in the future. One of the most effective strategies in this regard can be the use of a combination of PCL and biocompatible materials or polymers. Therefore, a careful examination of these strategies and finding materials that have the greatest compatibility with the polymer can increase the patients and physicians' satisfaction and thus render the progress and development of tissue engineering science.

\section{Ethical Approval \\ Not applicable.}

\section{Competing Interests}

Authors declare no competing interests.

\section{Acknowledgements}

This research was supported by Biomedical Engineering Laboratory (Central Lab), University of Sistan and Baluchestan, Zahedan, Iran.

\section{References}

1. Rocco KA, Maxfield MW, Best CA, Dean EW, Breuer CK. In vivo applications of electrospun tissue-engineered vascular grafts: a review. Tissue Eng Part B Rev. 2014;20(6):628-640. doi:10.1089/ten.teb.2014.0123.

2. Yalcin I, Horakova J, Mikes P, Sadikoglu TG, Domin R, Lukas D. Design of polycaprolactone vascular grafts. J Ind Text. 2016;45(5):813-833. doi:10.1177/1528083714540701.

3. Swartz DD, Andreadis ST. Animal models for vascular tissue-engineering. Curr Opin Biotechnol. 2013;24(5):916925. doi:10.1016/j.copbio.2013.05.005

4. Thomas AC, Campbell GR, Campbell JH. Advances in vascular tissue engineering. Cardiovasc Pathol. 2003;12(5):271-276. doi:10.1016/S1054-8807(03)00086-3

5. Conte MS. The ideal small arterial substitute: a search for the Holy Grail? FASEB J. 1998;12(1):43-45.

6. Nerem RM, Sambanis A. Tissue engineering: from biology to biological substitutes. Tissue Eng. 1995;1(1):3-13. doi:10.1089/ten.1995.1.3

7. Chiu LLY, Chu Z, Radisic M. Tissue Engineering. In: Scholes GD, Wiederrecht GP, eds. Comprehensive Nanoscience and Technology. Amsterdam: Academic Press; 2011:175211

8. Huang Z-M, Zhang Y-Z, Kotaki M, Ramakrishna S. A review on polymer nanofibers by electrospinning and their applications in nanocomposites. Compos Sci Technol. 2003;63(15):2223-2253. doi:10.1016/S02663538(03)00178-7

9. Beachley V, Wen X. Polymer nanofibrous structures: Fabrication, biofunctionalization, and cell interactions. Prog Polym Sci. 2010;35(7):868-892. doi:10.1016/j. progpolymsci.2010.03.003.

10. Bhardwaj N, Kundu SC. Electrospinning: a fascinating fiber fabrication technique. Biotechnol Adv. 2010;28(3):325-347. doi:10.1016/j.biotechadv.2010.01.004.

11. Ramakrishna S. An introduction to electrospinning and nanofibers. World Scientific; 2005

12. Zhang WJ, Liu W, Cui L, Cao Y. Tissue engineering of blood vessel. J Cell Mol Med. 2007;11(5):945-957. doi:10.1111/ j.1582-4934.2007.00099.x

13. Thottappillil N, Nair PD. Scaffolds in vascular regeneration: current status. Vasc Health Risk Manag. 2014;11:79-91. doi:10.2147/VHRM.S50536

14. Thomson RC, Wake MC, Yaszemski MJ, Mikos A. Biodegradable polymer scaffolds to regenerate organs. In: Peppas NA, Langer RS, eds. Biopolymers II. Berlin, Heidelberg: Springer; 1995:245-274. Advances in Polymer Science (POLYMER). vol 122.

15. Khang G, Kim SH, Kim MS, Lee HB. Hybrid, Composite, and Complex Biomaterials for Scaffolds A2 - Atala, Anthony. In: Lanza R, Thomson JA, Nerem RM, eds. Principles of Regenerative Medicine. San Diego: Academic Press; 2008:636-655.

16. Hubbell JA. Biomaterials in tissue engineering. Nat Biotechnol. 1995;13(6):565-576. doi:10.1038/nbt0695-565.

17. Deutsch M, Meinhart J, Zilla $P$, et al. Long-term experience in autologous in vitro endothelialization of infrainguinal ePTFE grafts. J Vasc Surg. 2009;49(2):352362. doi:10.1016/j.jvs.2008.08.101.

18. Sayers R, Raptis S, Berce M, Miller J. Long-term results of femorotibial bypass with vein or polytetrafluoroethylene. Br J Surg. 1998;85(7):934-938. doi:10.1046/j.13652168.1998.00765.x.

19. Jing X, Mi H-Y, Salick MR, Cordie TM, Peng X-F, Turng L-S. Electrospinning thermoplastic polyurethane/ graphene oxide scaffolds for small diameter vascular graft applications. Mater Sci Eng C. 2015;49:40-50. doi:10.1016/j. msec.2014.12.060.

20. Punnakitikashem P, Truong D, Menon JU, Nguyen KT, Hong Y. Electrospun biodegradable elastic polyurethane scaffolds with dipyridamole release for small diameter vascular grafts. Acta Biomater. 2014;10(11):4618-4628. doi:10.1016/j.actbio.2014.07.031.

21. Al Meslmani B, Mahmoud G, Strehlow B, Mohr E, Leichtweiß T, Bakowsky U. Development of thrombusresistant and cell compatible crimped polyethylene terephthalate cardiovascular grafts using surface coimmobilized heparin and collagen. Mater Sci Eng C. 2014;43:538-546. doi:10.1016/j.msec.2014.07.059

22. Giol ED, Schaubroeck D, Kersemans K, De Vos F, Van Vlierberghe S, Dubruel P. Bio-inspired surface modification of PET for cardiovascular applications: case study of gelatin. Colloids Surf B Biointerfaces. 2015;134:113-121. doi:10.1016/j.colsurfb.2015.04.035.

23. Chandra R, Rustgi R. Biodegradable polymers. Prog Polym Sci. 1998;23(7):1273-1335. doi:10.1016/S00796700(97)00039-7.

24. Nair LS, Laurencin CT. Biodegradable polymers as biomaterials. Prog Polym Sci. 2007;32(8):762-798. doi:10.1016/j.progpolymsci.2007.05.017.

25. Woodruff MA, Hutmacher DW. The return of a forgotten polymer-polycaprolactone in the 21st century. Prog Polym Sci. 2010;35(10):1217-1256. doi:10.1016/j. progpolymsci.2010.04.002.

26. Labet M, Thielemans W. Synthesis of polycaprolactone: a review. Chem Soc Rev. 2009;38(12):3484-3504. doi:10.1039/B820162P.

27. de Valence S, Tille JC, Mugnai D, et al. Long term performance of polycaprolactone vascular grafts in a rat abdominal aorta replacement model. Biomaterials. 2012;33(1):38-47. doi:10.1016/j.biomaterials.2011.09.024.

28. Kanani AG, Bahrami SH. Effect of changing solvents on 
poly ( $\varepsilon$-caprolactone) nanofibrous webs morphology. J Nanomater. 2011;2011:31. doi:10.1155/2011/724153.

29. Dias J, Bártolo P. Morphological Characteristics of electrospun PCL meshes-the influence of solvent type and concentration. Procedia CIRP. 2013;5:216-221. doi:10.1016/j.procir.2013.01.043.

30. Van der Schueren L, De Schoenmaker B, Kalaoglu ÖI, De Clerck K. An alternative solvent system for the steady state electrospinning of polycaprolactone. Eur Polym J. 2011;47(6):1256-1263. doi:10.1016/j. eurpolymj.2011.02.025.

31. Lee K, Kim H, Khil M, Ra Y, Lee D. Characterization of nano-structured poly ( $\varepsilon$-caprolactone) nonwoven mats via electrospinning. Polymer. 2003;44(4):1287-1294. doi:10.1016/S0032-3861(02)00820-0.

32. Nottelet B, Pektok E, Mandracchia D, et al. Factorial design optimization and in vivo feasibility of poly $(\varepsilon-$ caprolactone)-micro-and nanofiber-based small diameter vascular grafts. J Biomed Mater Res A. 2009;89(4):865-875. doi:10.1002/jbm.a.32023

33. Luo C, Stride E, Edirisinghe M. Mapping the influence of solubility and dielectric constant on electrospinning polycaprolactone solutions. Macromolecules. 2012;45(11):4669-4680. doi:10.1021/ma300656u.

34. de Valence S, Tille JC, Giliberto JP, et al. Advantages of bilayered vascular grafts for surgical applicability and tissue regeneration. Acta Biomater. 2012;8(11):3914-3920. doi:10.1016/j.actbio.2012.06.035

35. Wang Z, Cui Y, Wang J, et al. The effect of thick fibers and large pores of electrospun poly ( $\varepsilon$-caprolactone) vascular grafts on macrophage polarization and arterial regeneration. Biomaterials. 2014;35(22):5700-5710. doi:10.1016/j.biomaterials.2014.03.078.

36. Drilling S, Gaumer J, Lannutti J. Fabrication of burst pressure competent vascular grafts via electrospinning: effects of microstructure. J Biomed Mater Res A. 2009;88(4):923-934. doi:10.1002/jbm.a.31926.

37. Lee SJ, Oh SH, Liu J, Soker S, Atala A, Yoo JJ. The use of thermal treatments to enhance the mechanical properties of electrospun poly ( $\varepsilon$-caprolactone) scaffolds. Biomaterials. 2008;29(10):1422-1430. doi:10.1016/j. biomaterials.2007.11.024.

38. Serrano MC, Portolés MT, Vallet-Regí M, et al. Vascular endothelial and smooth muscle cell culture on $\mathrm{NaOH}$ Treated Poly ( $\varepsilon$-caprolactone) films: a preliminary study for vascular graft development. Macromol Biosci. 2005;5(5):415-423. doi:10.1002/mabi.200400214.

39. Mijovic B, Tominac TM, Agic A, et al. Study on cell adhesion detection onto biodegradable electrospun PCL scaffolds. JFBI. 2012;5:33-40. doi:10.3993/jfbi03201202

40. de Valence $\mathrm{S}$, et al. Plasma treatment for improving cell biocompatibility of a biodegradable polymer scaffold for vascular graft applications. Eur J Pharm Biopharm. 2013;85(1):78-86. doi:10.1016/j.ejpb.2013.06.012.

41. Hadjizadeh A, Mohebbi-Kalhori D. Porous hollow membrane sheet for tissue engineering applications. J Biomed Mater Res A. 2010;93(3):1140-1150. doi:10.1002/ jbm.a.32608.

42. Zhu Y, Cao Y, Pan J, Liu Y. Macro-alignment of electrospun fibers for vascular tissue engineering. J Biomed Mater Res B Appl Biomater. 2010;92(2):508-516. doi:10.1002/ jbm.b.31544.

43. Tiaw K, Goh S, Hong M, Wang Z, Lan B, Teoh S.
Laser surface modification of poly ( $\varepsilon$-caprolactone) (PCL) membrane for tissue engineering applications. Biomaterials. 2005;26(7):763-769.

44. Choi Hw, Johnson JK, Nam J, Farson DF, Lannutti J. Structuring electrospun polycaprolactone nanofiber tissue scaffolds by femtosecond laser ablation. J Laser Appl. 2007;19(4):225-231. doi:10.2351/1.2795749.

45. Pham QP, Sharma U, Mikos AG. Electrospun poly ( $\varepsilon$-caprolactone) microfiber and multilayer nanofiber/ microfiber scaffolds: characterization of scaffolds and measurement of cellular infiltration. Biomacromolecules. 2006;7(10):2796-2805. doi:10.1021/bm060680j.

46. Wang X, Lin P, Yao Q, Chen C. Development of smalldiameter vascular grafts. World J Surg. 2007;31(4):682-689. doi:10.1007/s00268-006-0731-z.

47. Kuwabara F, et al. Novel small-caliber vascular grafts with trimeric peptide for acceleration of endothelialization. Ann Thorac Surg. 2012;93(1):156-163. doi:10.1016/j. athoracsur.2011.07.055.

48. Zheng W, et al. Endothelialization and patency of RGDfunctionalized vascular grafts in a rabbit carotid artery model. Biomaterials. 2012;33(10):2880-2891. doi:10.1016/j. biomaterials.2011.12.047.

49. Ku SH, Park CB. Human endothelial cell growth on musselinspired nanofiber scaffold for vascular tissue engineering. Biomaterials. 2010;31(36):9431-9437. doi:10.1016/j. biomaterials.2010.08.071.

50. Ma Z, He W, Yong T, Ramakrishna S. Grafting of gelatin on electrospun poly (caprolactone) nanofibers to improve endothelial cell spreading and proliferation and to control cell orientation. Tissue Eng. 2005;11(7-8):1149-1158. doi:10.1089/ten.2005.11.1149.

51. Luong-Van E, Grøndahl L, Chua KN, Leong KW, Nurcombe V, Cool SM. Controlled release of heparin from poly ( $\varepsilon$-caprolactone) electrospun fibers. Biomaterials. 2006;27(9):2042-2050. doi:10.1016/j. biomaterials.2005.10.028.

52. Xiong GM, Yuan S, Wang JK, et al. Imparting electroactivity to polycaprolactone fibers with heparin-doped polypyrrole: modulation of hemocompatibility and inflammatory responses. Acta Biomater. 2015;23:240-249. doi:10.1016/j. actbio.2015.05.003

53. Mugnai D, Tille JC, Mrówczyński W, et al. Experimental noninferiority trial of synthetic small-caliber biodegradable versus stable vascular grafts. J Thorac Cardiovasc Surg. 2013;146(2):400-407. e401. doi:10.1016/j.jtcvs.2012.09.054.

54. Ahn H, Ju YM, Takahashi $\mathrm{H}$, et al. Engineered small diameter vascular grafts by combining cell sheet engineering and electrospinning technology. Acta Biomater. 2015;16:14-22. doi:10.1016/j.actbio.2015.01.030.

55. Ju YM, San Choi J, Atala A, Yoo JJ, Lee SJ. Bilayered scaffold for engineering cellularized blood vessels. Biomaterials. 2010;31(15):4313-4321. doi:10.1016/j. biomaterials.2010.02.002.

56. Lee SJ, Liu J, Oh SH, Soker S, Atala A, Yoo JJ. Development of a composite vascular scaffolding system that withstands physiological vascular conditions. Biomaterials. 2008;29(19):2891-2898. doi:10.1016/j.biomaterials.2008.03.032

57. Venugopal J, Ma L, Yong T, Ramakrishna S. In vitro study of smooth muscle cells on polycaprolactone and collagen nanofibrous matrices. Cell Biol Int. 2005;29(10):861-867. doi:10.1016/j.cellbi.2005.03.026 
58. Tillman BW, Yazdani SK, Lee SJ, Geary RL, Atala A, Yoo JJ. The in vivo stability of electrospun polycaprolactonecollagen scaffolds in vascular reconstruction. Biomaterials. 2009;30(4):583-588. doi:10.1016/j. biomaterials.2008.10.006.

59. Wise SG, Byrom MJ, Waterhouse A, Bannon PG, Ng MKC, Weiss AS. A multilayered synthetic human elastin/ polycaprolactone hybrid vascular graft with tailored mechanical properties. Acta Biomater. 2011;7(1):295-303. doi:10.1016/j.actbio.2010.07.022

60. Hong S, Kim G. Fabrication of electrospun polycaprolactone biocomposites reinforced with chitosan for the proliferation of mesenchymal stem cells. Carbohydr Polym. 2011;83(2):940-946. doi:10.1016/j.carbpol.2010.09.002.

61. Williamson MR, Black R, Kielty C. PCL-PU composite vascular scaffold production for vascular tissue engineering: attachment, proliferation and bioactivity of human vascular endothelial cells. Biomaterials. 2006;27(19):3608-3616. doi:10.1016/j.biomaterials.2006.02.025.

62. Nguyen T-H, Padalhin AR, Seo HS, Lee B-T. A hybrid electrospun PU/PCL scaffold satisfied the requirements of blood vessel prosthesis in terms of mechanical properties, pore size, and biocompatibility. J Biomater Sci Polym Ed. 2013;24(14):1692-1706. doi:10.1080/09205063.2013.7926 42.

63. McClure MJ, Sell SA, Simpson DG, Walpoth BH, Bowlin GL. A three-layered electrospun matrix to mimic native arterial architecture using polycaprolactone, elastin, and collagen: a preliminary study. Acta Biomater. 2010;6(7):2422-2433. doi:10.1016/j.actbio.2009.12.029.

64. Du F, Wang H, Zhao W, et al. Gradient nanofibrous chitosan/poly $\varepsilon$-caprolactone scaffolds as extracellular microenvironments for vascular tissue engineering. Biomaterials. 2012;33(3):762-770. 